Original Article

\title{
ROLE OF ELECTROENCEPHALOGRAME IN DIAGNOSIS OF ATTENTION DEFICIT HYPER ACTIVITY DISORDER
}

\author{
Alaa Zidan Ibrahim ${ }^{1}$, Mohammed Ahmed Talat ${ }^{1}$, Usama Mahmoud Yossef ${ }^{2}$, Amr Ibrahim \\ Mohammed $^{1}$ \\ 1Pediatrics Department, Faculty of Medicine, Zagazig University, Zagazig, Egypt \\ 2 Psychiatry Department, Faculty of Medicine, Zagazig University, Zagazig, Egypt
}

Corresponding author:

Amr Ibrahim Mohammed

Pediatrics Department,

Faculty of Medicine, Zagazig

University, Zagazig, Egypt

dr.amribrahim@ymail.com

$\begin{array}{ll}\text { Submit Date } & 2019-02-21 \\ \text { Revise Date } & 2019-03-01 \\ \text { Accept Date } & 2019-03-01\end{array}$

\section{ABSTRACT}

Introduction: Attention deficit hyper activity disorder (ADHD), is the most prevalent neurodevelopmental disorder of childhood, which is characterized by the presence of inattention, hyperactivity, and/or impulsivity, EEG is the substrate of brain activity underlying cognition and behavior.

Objective: To detect the abnormalities in the electroencephalogram (EEG) in patients with ADHD also to find the relation between attention deficit hyperactivity disorder symptom severity and results of EEG.

Method: sixty patients of ADHD and 60 age and sex matched control were evaluated with EEG to detect abnormal waves.

Results: Patients with ADHD show abnormal EEG results in the form of background slowing in 3 patients (5\%) and epileptiform discharge in 19 patients (32\%) frontal slowing in 13 patients(22\%) normal EEG in 25 patients $(42 \%)$.

Conclusion: There is increased low frequency activity and decreased high frequency activity in children with ADHD, this may aid as an indicator in the diagnosis of ADHD

Keywords: ADHD, epilepsy, Electroencephalogram EEG.

\section{INTRODUCTION}

ttention-Deficit/Hyperactivity Disorder (ADHD) is a developmental disorder of executive function that impairs the ability to focus, increases impulsivity, and increases motor activity. The condition is usually diagnosed between the ages of 6 to 12, but symptoms can persist into adulthood. Treatment of adults with persistent symptoms is becoming increasingly common ${ }^{[1]}$.

ADHD is an impairing neuropsychiatric, neurodevelopmental debilitating disorder with preschool onset and persistent childhood condition ${ }^{[2]}$.

It is characterized by symptoms of developmental, inappropriate hyperactivity, inattention and impulsive behavior ${ }^{[3]}$.

ADHD is a disorder with multiple etiologies, combinations of genetic, neurological, and environmental factors contribute to pathogenesis and its heterogeneous phenotype [4].
Recent studies suggest that ADHD is polygenic, and a variety of genes contribute to the development of the disorder. At the neurochemical level, both dopamine and norepinephrine are implicated with pharmaceutical intervention targeting these neurotransmitters ${ }^{[5]}$.

Executive function occurs in the prefrontal cortex. Dopamine plays an essential role in the cortex in maintaining this function. Dopaminergic neurons participate in the regulation of expectation, memory, activity, attention, reward, emotional state, and motivation .The dopamine system is highly sensitive to hypoxia, particularly in the fetus or infant. Thus any event, pre- or postnatally, that disrupts the flow of blood or oxygen to the brain might set the stage for later attention deficit hyperactivity disorder behaviors ${ }^{[6]}$.

Close relationship exists between attentiondeficit hyperactivity disorder (ADHD) and epilepsy ${ }^{[7]}$. 
Concerning electroencephalography, the prevalence of subclinical epileptiform discharges range from $4.9 \%$ to $60 \%$ in ADHD children without clinical seizures was shown. Subclinical epileptiform discharges are predominantly focal (bilateral or right sided) mostly over rolandic areas. Subclinical electroencephalographic epileptiform activity during sleep affects cognition and behavior in children with rolandic epilepsy ${ }^{[8]}$.

Epilepsy and ADHD may be two different independent expressions of a common underlying neurobiological abnormality ${ }^{[9]}$.

Another common finding in ADHD patients is excess slow-wave activity and increased epileptiform spike and wave activity. These findings were thought to suggest under arousal and maturational delay as underlying patho-physiologies in ADHD. Furthermore, children with ADHD who had greater excess slow-wave activity were more likely to have a positive response to stimulant medication, a finding that fits well with cortical under arousal theories, EEG studies in ADHD research have helped to clarify and refine these early findings ${ }^{[10]}$.

\section{SUBJECTS AND METHODS}

The study (case-control study) was held at Zagazig University Hospitals; Pediatrics and Psychiatry outpatient clinics in the period between September 2016 to January 2018.

Patient group involve 60 patient (42 male and 18 female) presenting with attention deficit hyperactivity disorder fulfilling the inclusion criteria of Diagnostic and Statistical Manual of mental disorders IV-TR ${ }^{[1]}$ and ranging in age from 6 years to 12 years with a mean age 8. $3 \pm 1.8$ years, control group age and sex matched were recruited for comparison.

Written informed consent should be obtained from all participants and the study should be approved by the research ethical committee of Faculty of Medicine, Zagazig University. The work should be carried out in accordance with The Code of Ethics of the World Medical Association (Declaration of Helsinki) for studies involving humans.

All patients in the study were subjected to the following:

1-Full history taking including: Proper history taking to detect factors predisposing to
ADHD this include pregnancy history and history of peri-partum hypoxia, developmental history including motor and mental and speech history, medical history for exclusion of any concurrent medical disorders, family history of similar conditions and history of any other psychiatric illness, parent judgment of school achievement to assess learning disorders.

2- Full general examination to exclude cases with medical illness.

3- Full neurological examination including standardized examination of motor system, sensory system, cranial nerves, gait and coordination.

4- Clinical psychiatric assessment based on items of Diagnostic and Statistical Manual of mental disorders IV-TR (DSM-IV-TR) criteria ,assessment of severity was performed using ADHDT (attention deficit hyper activity disorder test) which is 36 items scale which compromise basic aspects of the disorder (hyperactivity-impulsivity-inattentiveness).

5- EEG study to detect electroencephalographic changes in the patient fulfilling inclusion criteria.

Procedure of EEG

Electroencephalography (EEG) was done to all patients using the Stellate Harmonie system. This system has a standard number of 28 channels. During this procedure, the EEG is recorded, accompanied by continuous observation of patients.

During EEG monitoring, the patient wears an EEG transmitter connected to coaxial cable.

EEG signals are transmitted to the EEG recording device,

The entire duration of the EEG evaluation was analyzed, a sharp wave was considered epileptiform when it had a sharp morphology, duration of $<200 \mathrm{~ms}$, and was clearly distinct from EEG background.

Each EEG was analyzed by visual inspection to comment on:

- Background activity frequency and amplitude during wakefulness

- Presence of any abnormal activity (e.g. sharp waves, slow waves and spike-slow wave complexes)

- Symmetry between both hemispheres.

- Effect of Provocative techniques: photic stimulation, hyperventilation. 


\section{STATISTICAL ANALYSIS}

All statistical analyses were performed using IBM SPSS Statistics, version 24 (IBM; Armonk, New York, USA).

Continuous variables were presented as mean \pm SD or median (range).

Categorical variables were presented by the frequency and percentage. Normality was checked by Shapiro-Wilk test. Homogeneity of variance was checked by Levene's test.

Independent samples t-test: is used to determine if a difference exists between the means of two independent groups on a continuous dependent variable.

Chi-squared test of association: is used to discover if there is a relationship between two categorical variables.

Fisher's Exact Test: for (2X2) (RXC) table. It is used to discover if there is a relationship between two categorical variables. It is an alternative to chi-squared test when the expected cell count is less than five.

McNemar's test: is used to determine if there are differences on a dichotomous dependent variable between two related groups (before and after test).

\section{Diagnostic test evaluation}

- Sensitivity: probability that a test result will be positive when the disease is present (true positive rate).

- Specificity: probability that a test result will be negative when the disease is not present (true negative rate).

- Positive predictive value: probability that the disease is present when the test is positive.

- Negative predictive value: probability that the disease is not present when the test is negative.

- Accuracy: overall probability that a patient will be correctly classified.

\section{Significance level:}

$P$-value $<.05$ indicates a significant difference, $P<.01$ indicates a highly significant difference, $P<.001$ indicates a very highly significant difference while, $P \geq .05$ indicates a non-significant difference.

\section{RESULTS}

Table 1 Baseline characteristics of the studied children

\begin{tabular}{|c|c|c|c|c|}
\hline Characteristics & $\begin{array}{l}\text { Cases } \\
n=60\end{array}$ & $\begin{array}{l}\text { Controls } \\
n=60\end{array}$ & Test of significance & $P$-value \\
\hline Age (years) & & & \multirow{3}{*}{$\begin{array}{l}\text { Independent sample } \\
\text { t-test }=1.5\end{array}$} & \multirow[t]{3}{*}{.14} \\
\hline mean \pm SD & $8.3 \pm 1.8$ & $8.7 \pm 1.3$ & & \\
\hline median(range) & $8(6-12)$ & $9(6-12)$ & & \\
\hline Sex, $\boldsymbol{n}(\%)$ & & & \multirow[t]{3}{*}{ Fisher's exact test } & \multirow[t]{3}{*}{.84} \\
\hline Girls & $18(30)$ & $24(40)$ & & \\
\hline Boys & $42(70)$ & $36(60)$ & & \\
\hline
\end{tabular}

Table 2 Association between school achievement* and severity of ADHD

\begin{tabular}{|c|c|c|c|c|c|}
\hline \multicolumn{2}{|c|}{ *School achievement } & \multicolumn{3}{|c|}{ Severity } & \multirow[t]{2}{*}{ Total } \\
\hline & & Mild & Moderate & Severe & \\
\hline \multirow[t]{2}{*}{ Good } & $n$ & 5 & 5 & $\mathbf{0}$ & 10 \\
\hline & $\%$ & 23 & 25 & $\mathbf{0}$ & \\
\hline \multirow[t]{2}{*}{ Poor } & $n$ & 17 & 15 & 18 & \\
\hline & $\%$ & 77 & 75 & 100 & \\
\hline \multirow[t]{2}{*}{ Total } & $n$ & 22 & 20 & 18 & 60 \\
\hline & $\%$ & 100 & 100 & 100 & 100 \\
\hline \multicolumn{6}{|c|}{ Chi-squared for trend=33.1 } \\
\hline
\end{tabular}


Table 3 family history of psychiatric disorders

\begin{tabular}{|c|c|c|c|c|}
\hline Characteristics & $\begin{array}{l}\text { Cases } \\
n=60\end{array}$ & $\begin{array}{l}\text { Controls } \\
n=60\end{array}$ & Test of significance & $P$-value \\
\hline $\begin{array}{l}\text { Family history of } \\
\text { psychiatric illness, n (\%) }\end{array}$ & & & \multirow[t]{3}{*}{$\chi^{2}=5.9$} & \multirow[t]{3}{*}{.015} \\
\hline Negative & $54(95)$ & $58(97)$ & & \\
\hline Positive & $6(5)$ & $2(3)$ & & \\
\hline
\end{tabular}

Table4: Association between EEG findings and severity of ADHD

\begin{tabular}{|c|c|c|c|c|c|}
\hline \multicolumn{2}{|l|}{ EEG findings } & \multicolumn{3}{|c|}{ Severity } & \multirow[t]{2}{*}{ Total } \\
\hline & & Mild & Moderate & Severe & \\
\hline \multirow[t]{2}{*}{ Back ground slowing } & $n$ & 0 & 1 & 2 & 3 \\
\hline & $\%$ & 0 & 10 & 12 & 9 \\
\hline \multirow[t]{2}{*}{ Epileptiform discharge } & $n$ & 6 & 9 & 4 & 19 \\
\hline & $\%$ & 75 & 90 & 22 & 54 \\
\hline \multirow[t]{2}{*}{ Frontal slowing } & $n$ & 2 & 0 & 11 & 13 \\
\hline & $\%$ & 25 & 0 & 65 & 37 \\
\hline \multirow[t]{2}{*}{ Total } & $n$ & 8 & 10 & 17 & 35 \\
\hline & $\%$ & 100 & 100 & 100 & 100 \\
\hline Fisher's exact test $=14.8$ & & & \multicolumn{3}{|c|}{$P$-value $=.001$} \\
\hline
\end{tabular}

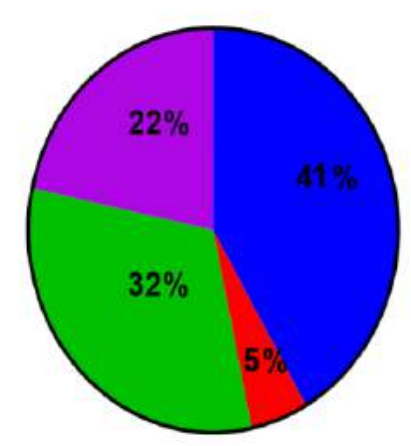

Fig 1- Pie chart represents percent of EEG findings in ADHD cases. 


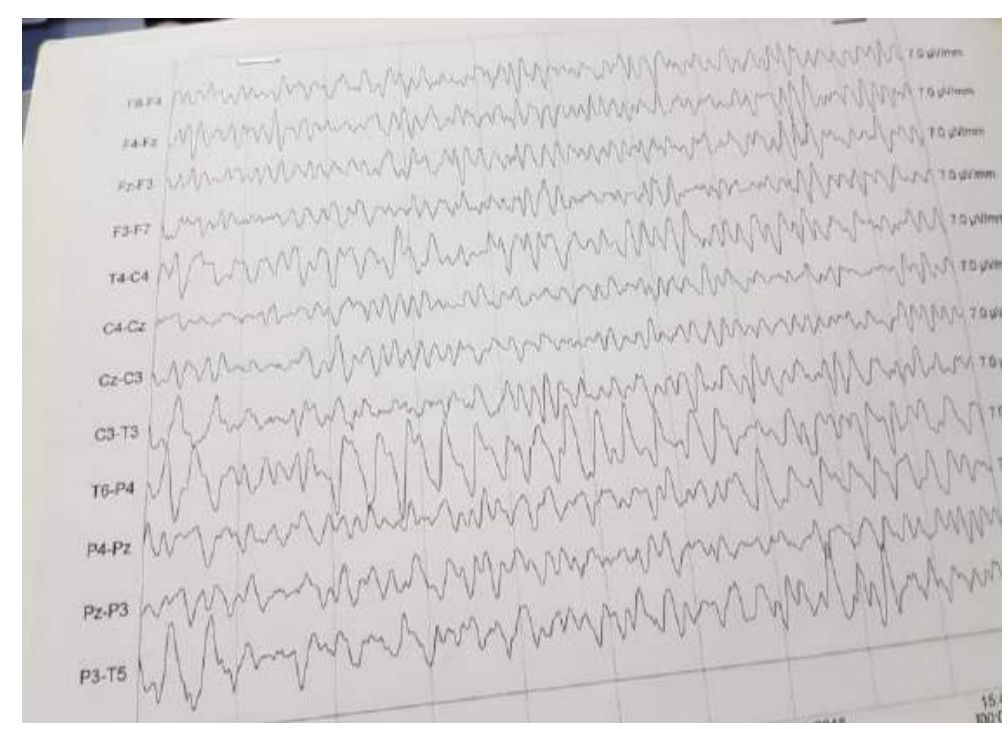

Fig 2 EEG tracing showing spikes and slow waves

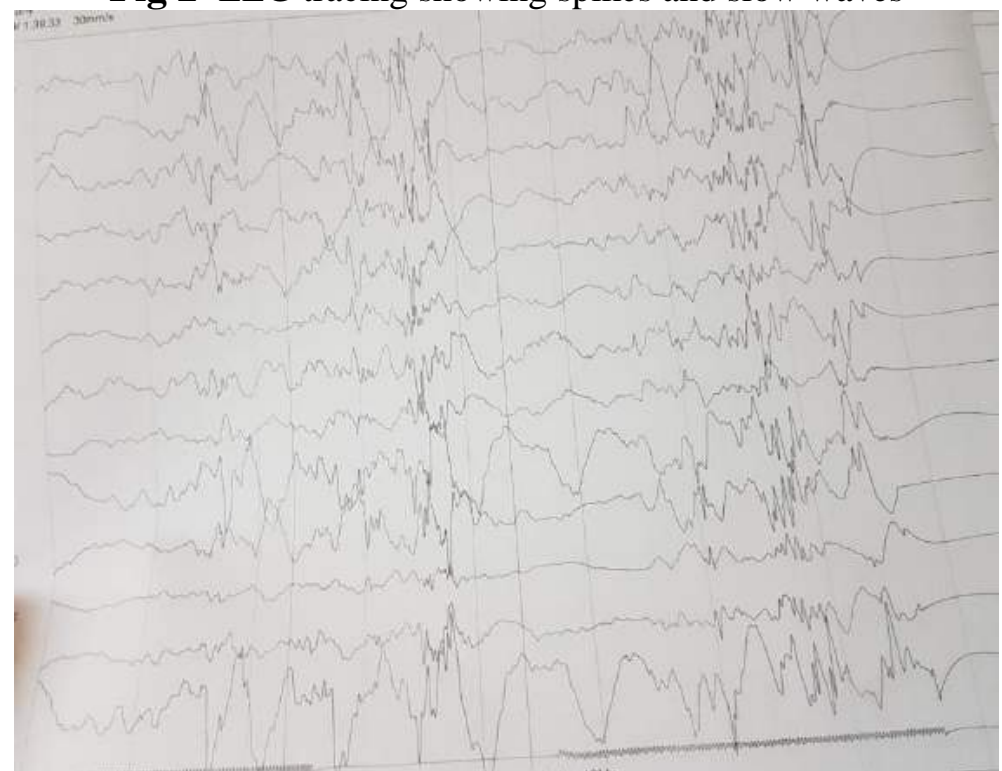

Fig 3 EEG tracing showing epileptiform discharge

\section{DISCUSSION}

Attention deficit hyperactivity disorder (ADHD) is a common pediatric neurodevelopmental disorder ${ }^{[12]}$.

The Core symptoms include a functionally significant level of inattentiveness and distractibility (difficulty staying on task, completing work) and also frequently involve impairments in executive functioning (organization, working memory), as well as increased behavioral and verbal impulsivity (talking out of turn, interrupting) and motor restlessness (difficulty remaining seated) ${ }^{[13]}$. Currently the number of patients diagnosed as ADHD during childhood and adolescence is increasing ${ }^{[14]}$.
Our study (case control) was held in Zagazig university hospitals outpatient clinic (pediatric neurology and psychiatry clinics) on 60 patient newly diagnosed clinically using Diagnostic and Statistical Manual of mental disorders IV(DSM-IV-TR) as ADHD, aged 6-12 years ,both genders where included, and on control group age and gender matched.

Patient and control groups were subjected to full history taking, including factors predisposing to ADHD, full general examination, full neurological examination and psychiatric evaluation.

Patient and control groups were investigated with electroencephalogram (EEG), to detect any abnormal waves. 
Since our sample was age and gender matched from the beginning, there were no age and gender significant differences. This denotes that the studied samples were homogenous as the mean age in attention deficit hyperactivity disorder patients was 8.3 $( \pm 1.8)$ years while in control group it was 8.3 $( \pm 1.3)$ years.

Regarding sex distribution among our patients , males were $70 \%$ of patient group (42 patient) and females where $30 \%$ (18 patient), this in agreement with Novik et al ., $2006^{[15]}$ who stated that ADHD is more commonly diagnosed in males, with the sex ratio ranging from 2:1 to 10:1, also Bruchmuller et al ., $\mathbf{2 0 1 2}^{[16]}$ found that the gender ratios of males to females in ADHD children were from 2:1 to $9: 1$ in clinical subjects and $2: 1$ to $3: 1$ in community samples.

In contrast to our study, Mitchison GM, Njardvik U., 2015 ${ }^{[17]}$ stated that there is no support for sex differences for ADHD symptoms and co-occurring problems in clinical samples.

Also Quinn PO., 2008 ${ }^{[18]}$ stated that females with ADHD are more likely to present with predominantly inattentive symptoms, and less hyperactive/ impulsive or conduct problems than males, and are thus perceived as less problematic

As for family history, there was significant difference between patients and control groups regarding the presence of psychiatric illness in one parent at least $(\mathrm{P}$ Value $=$ 0.015). This strongly suggests a hereditary basis to attention deficit hyperactivity disorder.

This agrees with Andrew S et al., 2107 ${ }^{[19]}$ who stated that socioeconomic status and parental history of ADHD are strong risk factors for ADHD that interact to determine prevalence

Also our results were consistent with Nigg, 2006 $^{[20]}$ who noted the higher prevalence of psychiatric diseases in the parents of children with ADHD where, $10-35 \%$ of the family members of children with ADHD are likely to have the disorder.

Also, Barkley et al., 2008 ${ }^{[21]}$ found that if a parent had attention deficit hyperactivity disorder, the risk of development of the disorder in his/her children reached 40-57\%.
The results of our study revealed very highly statistically significant association between school achievement and severity of ADHD $(P<.001)$ according to parent judgment of school achievement, this agrees with Garner et al., $\mathbf{2 0 1 3}^{[22]}$ who found that parent ratings of inattention and hyperactivity-impulsivity symptoms emerged as the strongest predictor of later academic underachievement.

Also Polderman et al., 2010 ${ }^{[23]}$ found that inattention is a core risk factor for poor academic achievement in both clinical and population based samples.

Lundervold et al., $2017^{[24]}$ found that features of inattention, in particular from a parent's perspective, are of crucial importance in predicting high-school achievement so, remediation of problems related to inattention may provide benefit not only for academic and later vocational problems but also for social interactions and general mental health Fried et al., 2016 ${ }^{[25]}$.

EEG findings in our study revealed the following results:- background slowing in $(5 \%)$ of patient while frontal slowing represent $(21.6 \%)$ and epileptiform discharge in $(31.6 \%)$ this goas hand by hand with Snyder and Hall, 2006 ${ }^{[26]}$ who reported that EEG abnormalities in children with ADHD , include excess slow-wave activity and increased epileptiform spike and wave activity.

Also in agreement with Ogrim et al., 2012 ${ }^{[27]}$ who stated that most children with ADHD display fairly consistent EEG differences in brain electrical activity as compared to normal children, particularly with respect to their increased fronto-central theta $(4-7 \mathrm{~Hz})$ activity during primarily resting state conditions.

There was a very high statistically significant association between EEG findings and severity of ADHD especially frontal slowing and epileptiform discharge $(P=.001)$, this agrees with Roessner et al., 2006 ${ }^{[28]}$ who found that impairment of executive functions - in particular inhibitory deficits- may be directly linked to brain abnormalities especially interictal epileptiform discharge.

Kim EH et al., 2014 ${ }^{[29]}$ found that there is significant negative impact of epileptiform 
discharge activation in patients with ADHD on their neuropsychological profiles.

\section{CONCLUSION}

From the results of our study we conclude than electroencephalogram (EEG) can be used side by side with clinical data in diagnosis of Attention deficit hyper activity disorder.

Declaration of interest

The authors report no conflicts of interest. The authors alone are responsible for the content and writing of the paper.

Funding information

None declared

\section{REFERENCES}

1- Smith ZR, Langberg JM: Review of the Evidence for Motivation Deficits in Youth with ADHD and Their Association with Functional Outcomes. Clin Child Fam Psychol 2018; Dec21(4):500-526 Rev. Aug 23

2- Faraone, S.V., Sergeant, J., Gillberg, C. \&Biederman, and $\mathbf{J}$ : The worldwide prevalence of ADHD: is it an American condition? World Psychiatry, 2003; 2, 104.

3- Talaei A, Mokhber N, Abdollahian E, Reza M, Bordbar F and Salari E: Attention deficit/hyperactivity disorder: A survey on prevalence rate among male subjects in elementary school (7 to 9 Years Old) in Iran. Journal of Attention Disorders 2010; 13: 386390.

4- Akutagava-Martins GC, Rohde LA, Hutz MH: Genetics of attentiondeficit/hyperactivity disorder: An update. Expert RevNeurother, 2016; 16(2):145-56.

5- Anjum I, Jaffery SS, Fayyaz M, Wajid A, AnsAH: Sugar Beverages and Dietary Sodas Impact on Brain Health: A Mini Literature Review. Cureus 2018;. Jun 07; 10 (6):e2756.

6- Decker, M.J. \& Rye, D.B: Neonatal intermittent hypoxia impairs dopamine signaling and executive functioning. Sleep and Breathing, 2002; 6, 205-210

7- Parisi P,Moavero R, Verrotti A, Curatolo P: Attention deficit hyperactivity disorder in children with epilepsy. Brain\& Development 2010; 32: 10 - 16.

8- Silvestri R, Gagliano A, Calarese T, Aric'o I, Cedro C, Condurso R, et al : Ictal and interictal EEG abnormalities in ADHD children recorded over night by videopolysomnography. Epilepsy Research 2007; $75,130-137$.

9- Kanemura H, Sano F, Tando T, Hosaka H, Sugita K, Aihara M, et al: EEG improvements with antiepileptic drug treatment can show a high correlation with behavioral recovery in children with ADHD. Epilepsy Behav; 2013; 27:443-8.

10- Snyder SM, Hall JR: A meta-analysis of quantitative EEG power associated with attention-deficit hyperactivity disorder. J ClinNeurophysiol.2006; 23:440-455.

11- American Psychiatric Association Diagnostic and Statistical Manual of Mental Disorders (DSM-IV-TR) Washington, DC: American Psychiatric Association Press Fourth Edition Text Revision 2000; (ISBN: 0890420254).

12- Goraya J, Cruz M, Valencia I, Kaleyias J, Khurana D, Hardison H, et: al Sleep study abnormalities in children with ADHD Pediatr Neurol 2009; 40:42-46.

13- Owens J, Sangal R, Sutton V, Bakken R, Allen $\mathbf{A}$ and Kelsey D: Subjective and objective measures of sleep in children with attention-deficit/hyperactivity disorder. Sleep Medicine2009; 10(4): 446-56.

14- Polanczyk GV, Willcutt EG, Salum GA: ADHD prevalence estimates across three decades: an updated systematic review and meta-regression analysis. Int $\mathrm{J}$ Epidemiol 2014; 43(2):434-42.

15- Novik TS, Hervas A, Ralston SJ et al: Influence of gender on attentiondeficit/hyperactivity disorder in Europe ADORE. Eur Child Adolesc Psychiatry 2006; 15:i15-i24.

16- Bruchmuller, K., Margraf, J., Schneider, S: Is ADHD diagnosed in accord with diagnostic criteria? Over diagnosis and influence of client gender on diagnosis .J. Consult. Clin.Psychol 2012; 80 (1), 128-138.

17- Mitchison GM, Njardvik U: Prevalence and gender differences of ODD, anxiety, and depression in a sample of children with ADHD. J Atten Disord2015.

18- Quinn PO: Attention-deficit/hyperactivity disorder and its comorbidities in women and girls: an evolving picture. Curr Psychiatry Rep 2008; 10:419-423.

19- Andrew S. Rowland, Betty J. Skipper, David L. Rabiner, Fares Qeadan, Richard A. Campbell, et al: AttentionDeficit/Hyperactivity Disorder (ADHD): Interaction between socioeconomic status and parental history of ADHD determines prevalence, Journal of Child Psychology and Psychiatry2017; doi:10.1111/jcpp.12775.

20- Nigg J T: What Causes ADHD? Understanding What Goes Wrong and Why. New York: Guilford Publications, 2006; 422 pp. ISBN 1-59385-297-3. 
21- Barkley R, Murphy $\mathbf{K}$ and Fischer $\mathbf{M}$ : ADHD in Adults: What the Science Says. New York: Guilford Publications2008; available

on

https://www.guilford.com/books/ADHD-in-

Adults/Barkley-Murphy-

Fischer/9781609180751/reviews.

22- Garner A, O'Connor BC, Narad ME., Tamm L, Simon J., and Epstein JN: The relationship between ADHD symptom dimensions, clinical correlates, and functional impairments, J. Dev. Behav. Pediatr 2013; 34, 469-477.

23- Polderman, T. J. C., Boomsma, D. I., Bartels, M., Verhulst, F. C., and Huizink, A. C: A systematic review of prospective studies on attention problems and academic achievement. Acta Psychiatr. Scand2010; 122, 271-284.

24- Lundervold Astri J., Jocelyn I. Meza, Mari Hysing and Stephen P. Hinshaw: Parent Rated Symptoms of Inattention in Childhood Predict High School Academic Achievement Across Two Culturally and Diagnostically Diverse Samples, Frontiers in Psychology August 2017 ; Volume 8 | Article 1436.
25- Fried, R., Petty, C., Faraone, S. V., Hyder, L. L., Day, H., and Biederman, J. : Is ADHD a risk factor for high school dropout? A controlled study. J. Atten. Disord2016; 20, 383-389.

26- Snyder SM, Hall JR: A meta-analysis of quantitative EEG power associated with attention-deficit hyperactivity disorder. J ClinNeurophysiol2006. 23:440-455.

27- Ogrim G, Kropotov J, Hestad K: The quantitative EEG theta/beta ratio in attention deficit/hyperactivity disorder and normal controls: Sensitivity, specificity, and behavioral correlates. Psychiatry Research2012; 198(3):482-488.

28- Roessner V, Banaschewski T, Rothenberger, A: Neuro psychological performance in ADHD and tic-disorders: a prospective 1-year follow-up.. 2006; 55, 314-327.

29- Kim EH, Yum MS, Kim HW, KO TS. Attention-deficit/hyperactivity disorder and attention impairment in children with benign childhood epilepsy with centrotemporal spikes. Epilepsy Behav2014; 37:54-8.

To cite this article: Ibrahim AZ, Talat MA, Yossef UM, Mohammed Al. Role of Electroencephalograme in Diagnosis of Attention Deficit Hyper Activity Disorder.,Egypt.ZUMJ 2019;25(3);439-446,DOI: 10.21608/zumj.2019.9784.1063 